\title{
Diagnostic accuracy of CT scan-based criteria compared with surgical exploration for the analysis of cervical fusion and nonunion
}

\author{
Martine W. T. van Bilsen, MD, ${ }^{1}$ Christopher Ullrich, MD, PhD, ${ }^{3}$ Luis Ferraris, MD, ${ }^{4}$ \\ Axel Hempfing, MD, ${ }^{5}$ Wolfgang Hitzl, PhD, ${ }^{6}$ Michael Mayer, MD, ${ }^{7}$ and Heiko Koller, MD ${ }^{2}$
}

\begin{abstract}
'Department of Neurosurgery, Radboud University Medical Center, Nijmegen, the Netherlands; '2Department of Neurosurgery, Klinikum rechts der Isar, Technical University Munich, Germany; ${ }^{3}$ Charlotte Radiology PA and Department of Radiology, Carolinas Medical Center, Charlotte, North Carolina; ${ }^{4}$ ATOS Orthopädische Klinik, Braunfels, Germany; ${ }^{5}$ Wirbelsäulenzentrum, Bad Wildungen, Germany; ${ }^{6}$ Research Office, Paracelsus Medical University, Salzburg, Austria; and ${ }^{7}$ Wirbelsäulenzentrum am Stiglmaierplatz, Munich, Germany
\end{abstract}

OBJECTIVE Computed tomography (CT) scans are accepted as the imaging standard of reference to define union after anterior cervical discectomy and fusion (ACDF). However, ideal CT criteria to diagnose union have not been identified or validated. The objective of this study was to analyze the diagnostic value of 9 CT-based criteria and identify the ideal criteria among them to assess cervical fusion after ACDF using surgical exploration as the standard of reference.

METHODS The authors performed a retrospective radiographic study of a single surgeon's prospective assessment of osseous fusion during cervical revision surgery by analyzing complete radiographic data in 44 patients who underwent anterior cervical revision surgery due to symptomatic suspected nonunion or adjacent level disease. All patients received standard preoperative CT scans, which were assessed by an independent radiologist to evaluate 9 diagnostic criteria for osseous union. During revision surgery, scar tissue was removed and manual segmental translation tests were performed. Nonunion was defined by visualized motion at the treated ACDF level.

RESULTS In total, 44 patients were included in the study ( 30 men; patient age $54 \pm 6$ years, BMI $28 \pm 5 \mathrm{~kg} / \mathrm{m}^{2}$ ). For analysis of fusion, 75 cervical levels were explored, of which 61 levels (81\%) showed intraoperative movement indicating nonunion. Statistical analysis showed that of the 9 parameters used to diagnose bone union, "bridging bone on $\geq 3$ CT slices" yielded the highest sensitivity (100\%) and specificity (58\%). Multivariate analysis revealed that prediction accuracy was not increased if several criteria were combined to determine fusion.

CONCLUSIONS The authors found that the best indicator of bone union was the item bridging bone on $\geq 3 \mathrm{CT}$ slices. Combining the scoring of more than one criterion did not increase the diagnostic accuracy.

https://thejns.org/doi/abs/10.3171/2019.12.SPINE191011

KEYWORDS anterior cervical discectomy and fusion; computed tomography; nonunion

$\Lambda$ NTERIOR cervical discectomy and fusion (ACDF) is the most common and efficient form of cervical spine surgery for treatment of degenerative disc disease. ${ }^{11}$ This method was first described in the literature by Smith and Robinson in $1958 .{ }^{19}$ The principle of ACDF is to remove the degenerative disc and fuse two or more vertebral bodies to form a single bony unit which prevents vertebral movement between the operated levels. ${ }^{16}$ This procedure has been proven very effective in the treatment of radiculopathy and myelopathy ${ }^{18}$ Clinical outcomes in patients who fail to achieve the intended bony fusion are worse than in patients who did attain this bony fusion., ${ }^{7,10,21}$ In addition, revision surgery for pseudoarthrosis in order to obtain fusion in patients with nonunion shows satisfactory results. ${ }^{7,12}$

The diagnosis of nonunion remains problematic. Previous studie ${ }^{1,4,6,14-16,18,20,21}$ have assessed nonunion with the support of imaging methods such as conventional radiog-

ABBREVIATIONS ACDF = anterior cervical discectomy and fusion; $\mathrm{AP}=$ anteroposterior; $\mathrm{CR}=$ computed radiography; $\mathrm{NPV}=$ negative predictive value; $\mathrm{PMMA}=$ polymethylmethacrylate; $P P V=$ positive predictive value; $R O M=$ range of motion .

SUBMITTED September 5, 2019. ACCEPTED December 5, 2019.

INCLUDE WHEN CITING Published online March 6, 2020; DOI: 10.3171/2019.12.SPINE191011. 
raphy or CT. While CT seems to have the highest accuracy, ideal criteria and validation studies are still lacking, which has resulted in the use of multiple divergent scoring systems reported in the literature for the assessment of nonunion. ${ }^{16}$ Intraoperative validation of bony fusion is considered the clinical reference standard. The diagnostic accuracies of CT-based fusion criteria are best evaluated when the comparison standard is anterior intraoperative confirmation. Previous studies ${ }^{1,6,20}$ either had small patient samples or used nonspecific scoring items. More importantly, their surgical approach was mainly posterior, which makes assessment of anterior fusion status less reliable due to the small cervical dimensions and elasticity of posterior bony elements and laminae. A posterior distraction test can result in a false-positive anterior column fusion assessment.

In this study we aimed to explore the diagnostic accuracy of 9 different CT scoring criteria for determining bony fusion or nonunion by using intraoperative anterior evaluation of segmental motion between bone and intersegmental cages, grafts, or spacers.

\section{Methods}

The hypothesis of this study was that criteria based on CT parameters can be used to diagnose bone union after ACDF with high specificity and sensitivity. We also hypothesized that combining 2 or more of these scoring criteria can improve specificity and sensitivity. We used a retrospective observational study to test these hypotheses. As the study was retrospective, it involved data collection, and no alterations to the standard of care for patient treatment were made. Assessment of anterior fusion was done by 2 experienced spine surgeons who worked together in anterior cervical revision surgery using the same criteria in any patient undergoing anterior cervical spine revision surgery.

Patients who were scheduled for revision surgery between September 2009 and November 2011 after previous ACDF were included in this study. Example cases are given in Fig. 1. Indications for these revisions were suspicion of nonunion, residual stenosis with or without symptomatic adjacent segment disease, and new stenosis of an adjacent level. Exclusion criteria were a history of posterior instrumentation or spinal infection after the previous surgery. Furthermore, patients with incomplete datasets were excluded from the study. All patients underwent a standard preoperative workup, which included cervical standard computed radiography (CR), dynamic CR, cervical MRI, and CT or CT myelography studies using 1-mm axial image thickness and postprocessed 2D sagittal and coronal plane reconstruction imaging. The CT scan was made at least 1 year postoperatively from the prior ACDF and less than 1 month prior to revision surgery. Data for additional variables such as sex, age, indication for scheduled surgery, number of previous anterior surgeries, previous anterior fusion levels, presence of a plate or cage and cage type, and use of a bone graft during previous surgery were extracted from the patient files.

\section{CT Imaging Technique}

CT datasets were obtained by scanning the patients in a supine position with a neutral head position using a 40-channel CT system. Axial 1-mm CT images were obtained using both soft tissue and bone algorithms. Postprocessed 2D sagittal and coronal reconstruction images were routinely obtained. These $\mathrm{CT}$ studies were evaluated by an independent and experienced neuroradiologist (C.U., a senior member of the Cervical Spine Research Society and past president and senior member of the American Society of Neuroradiology). Nine imaging criteria were selected to score the CT scans. These criteria were extracted from prior scientific work ${ }^{1,6,13,20}$ and compiled by the senior author (H.K.). They are stated and clarified in Table 1. All items were scored separately but in practice may be present in combinations.

\section{Surgical Procedure}

All surgeries were performed by the same surgeon. The study purpose did not alter normal surgical protocol, which consisted of surgical site opening using a Caspar retractor, customized spinal needles, and baby Hohmann retractors, followed by resection of prevertebral scar tissues covering the former disc space area and macroscopic testing of segmental range of motion (ROM) with either an anteroposterior (AP) translation test (Fig. 2A) or a cantilever angulation test (Fig. 2B) using a 4-mm thinned Lambott chisel inserted at any exposed surface between the cage and osseous endplate after removal of the anterior scar tissue. Nonunion was defined by visualized motion at the treated ACDF level.

\section{Statistical Analysis}

Results were evaluated using basic descriptive statistics. Sensitivity, specificity, positive predictive value (PPV), and negative predictive value (NPV) were computed for all of the different scoring items. Data consistency was checked and data were screened for outliers and normality by using quantile plots. Fisher's exact tests were used to analyze cross-tabulations. Unpaired Student t-tests, Welch t-tests, and Mann-Whitney U-tests were used to compare both groups. Levene's test was used to test for variance homogeneity, and 95\% CIs were computed for differences of means. Correlation analyses were done using Pearson's and Spearman's correlation coefficients. All reported tests were two-sided, and $\mathrm{p}$ values $<0.05$ were considered statistically significant. All statistical analyses in this report were performed with Statistica 10 (StatSoft).

\section{Results}

Of a total of 50 consecutive patients who underwent revision surgery after prior ACDF, 44 patients had complete datasets and were included in the study. The study population consisted of 30 men and 14 women (mean \pm SD age $54 \pm 6$ years, BMI $28 \pm 5 \mathrm{~kg} / \mathrm{m}^{2}$ ), and 19 patients were smokers (43\%). The number of previous surgeries was 1.3 \pm 0.5 , and the number of previous levels operated on was $1.8 \pm 0.7$. A total of 75 cervical levels were explored for analysis of fusion, including $3 \mathrm{C} 3-4$ levels (4\%), $7 \mathrm{C} 4-5$ levels (9\%), 36 C5-6 levels (48\%), 27 C6-7 levels (36\%), and 2 C7-Th1 levels (3\%). All levels had a cervical cage or an interbody spacer, and 14 cases (19\%) had a polymethyl- 

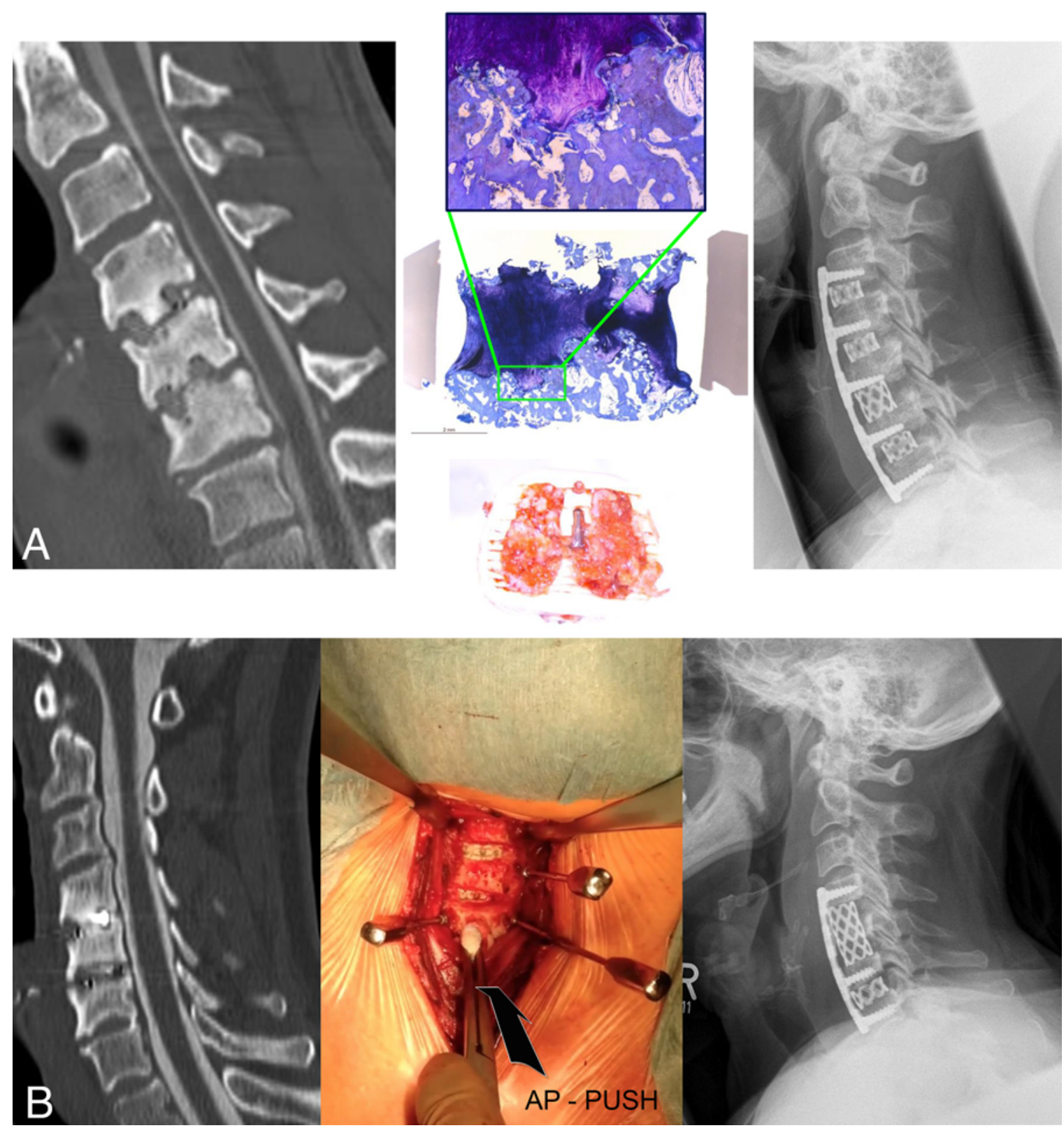

FIG. 1. A: Example images of a patient with nonunion at C4-7 as well as adjacent level degenerative disease, including sagittal CRs (left and right), histological reprocessing of retrieved cages by dehydration and embedding in acrylic resin (Technovit 7200) (lower center), and specialized cutting and staining using Toluidine blue (upper center). B: Example images of a patient with nonunion at C4-6 and symptomatic adjacent level disease, including sagittal CRs (left and right) and an intraoperative image (center) showing the application of AP pressure with a sponge instrument to test for mobility of the segment after scars were removed from the anterior aspect of the cervical spine. Figure is available in color online only.

methacrylate (PMMA) spacer, $16(21 \%)$ had a metal cage, and $45(60 \%)$ had a PEEK cage.

Intraoperative assessment showed nonunion in 61 levels (81\%), whereas with assessment based on the 9 CT criteria the mean number of levels with nonunion was $47(63 \% \pm$ $31 \%$ ). Multivariate logistic regression analysis showed no increase in diagnostic accuracy with the use of combinations of criteria (combined sensitivity $67 \%$ [95\% CI 38\%$88 \%$ ], combined specificity $85 \%$ [95\% CI 73\%-93\%]). The scoring item "bridging bone on $\geq 3$ CT-slices" yielded the highest sensitivity (100\%), with a specificity of 58\%. Sen- sitivity, specificity, PPV, and NPV values for all 9 CT scan criteria are displayed in Table 2.

\section{Discussion \\ Summary of Results}

The aim of this study was to determine the diagnostic accuracy of CT-based criteria for union after ACDF with high specificity and sensitivity and whether combining different scoring items improves specificity and sensitivity. According to the authors' knowledge, this study in- 
TABLE 1. Image criteria used to identify osseous union on CT scans

\begin{tabular}{|c|c|}
\hline CT Scan Criterion & Definition \\
\hline $\begin{array}{l}\text { Bridging bone on }>1 \mathrm{CT} \\
\text { slice, no lucency }\end{array}$ & $\begin{array}{l}\text { Any bone bridging of cancellous or cortical density reaching both cranial \& } \\
\text { caudal endplates of examined level, w/o lucent lines crossing margins, on >1 } \\
\text { coronal CT image. No lucency visible around cage. Bone may be present on } \\
\text { either side \&/or w/in cage. }\end{array}$ \\
\hline Bridging bone & $\begin{array}{l}\text { Any bone bridging of cancellous or cortical density reaching both cranial \& } \\
\text { caudal endplates of examined level, w/o lucent lines crossing margins, on } \geq 1 \\
\text { coronal plane CT image. Bone may be present on either side \&/or w/in cage. }\end{array}$ \\
\hline $\begin{array}{l}\text { Bridging bone on } \geq 3 \mathrm{CT} \\
\text { slices }\end{array}$ & $\begin{array}{l}\text { Any bone bridging of cancellous or cortical density reaching both cranial \& } \\
\text { caudal endplates of examined level, w/o lucent lines crossing margins, on } \geq 3 \\
\text { coronal plane CT images. Bone may be present on either side \&/or w/in cage. }\end{array}$ \\
\hline Upper endplate fusion & $\begin{array}{l}\text { Bone bridging of cortical density bridging graft-upper endplate gap of examined } \\
\text { level w/o lucency. }\end{array}$ \\
\hline Lower endplate fusion & $\begin{array}{l}\text { Bone bridging of cortical density bridging graft-lower endplate gap of examined } \\
\text { level w/o lucency. }\end{array}$ \\
\hline $\begin{array}{l}\text { Bridging bone anterior } \\
\text { to cage }\end{array}$ & $\begin{array}{l}\text { Any bone bridging of cancellous or cortical density anterior to cage reaching } \\
\text { both cranial \& caudal endplates of examined level in sagittal plane CT, w/o } \\
\text { lucent lines crossing margins. }\end{array}$ \\
\hline $\begin{array}{l}\text { Bridging bone posterior } \\
\text { to cage }\end{array}$ & $\begin{array}{l}\text { Any bone bridging of cancellous or cortical density posterior to cage reaching } \\
\text { both cranial \& caudal endplates of examined level in sagittal plane CT, w/o } \\
\text { lucent lines crossing margins. }\end{array}$ \\
\hline $\begin{array}{l}\text { Osseus integration } \\
\text { of cage at both } \\
\text { endplates }\end{array}$ & $\begin{array}{l}\text { Direct integration of bone of cortical or cancellous density into intervertebral } \\
\text { implant \& both endplates, w/o lucency. }\end{array}$ \\
\hline Bridging bone w/in cage & $\begin{array}{l}\text { Any bone bridging of cancellous or cortical density w/in cage reaching both cra- } \\
\text { nial \& caudal endplates of examined level, w/o lucent lines crossing margins. }\end{array}$ \\
\hline
\end{tabular}

cludes the largest sample analysis to date that compares fusion status assessment data obtained using anterior intraoperative exploration with data obtained using specific criteria applied to preoperative CT scans.

Statistical analysis showed that of the 9 parameters used to diagnose osseous union, the item "bridging bone on $\geq 3$ CT slices" yielded the highest cumulative accuracy, with a sensitivity of $100 \%$ and a specificity of $58 \%$. Bridging bone, independent of the number of CT slices it was seen on, yielded a sensitivity of $100 \%$, with varying specifici- ties of $28 \%-87 \%$. Multivariate logistic regression analysis showed no increased diagnostic accuracy with the use of any combination of the $9 \mathrm{CT}$ assessment criteria.

These results indicate that correct identification of osseous union was most likely when it was based on the finding of bridging bone on $\geq 3$ CT slices, with no cases of union being missed with the use of this method. However, the specificity of this method was no more than $58 \%$, a finding that translates into a low PPV of $38 \%$ and a much higher NPV of $100 \%$. Thus, intraoperative motion of the
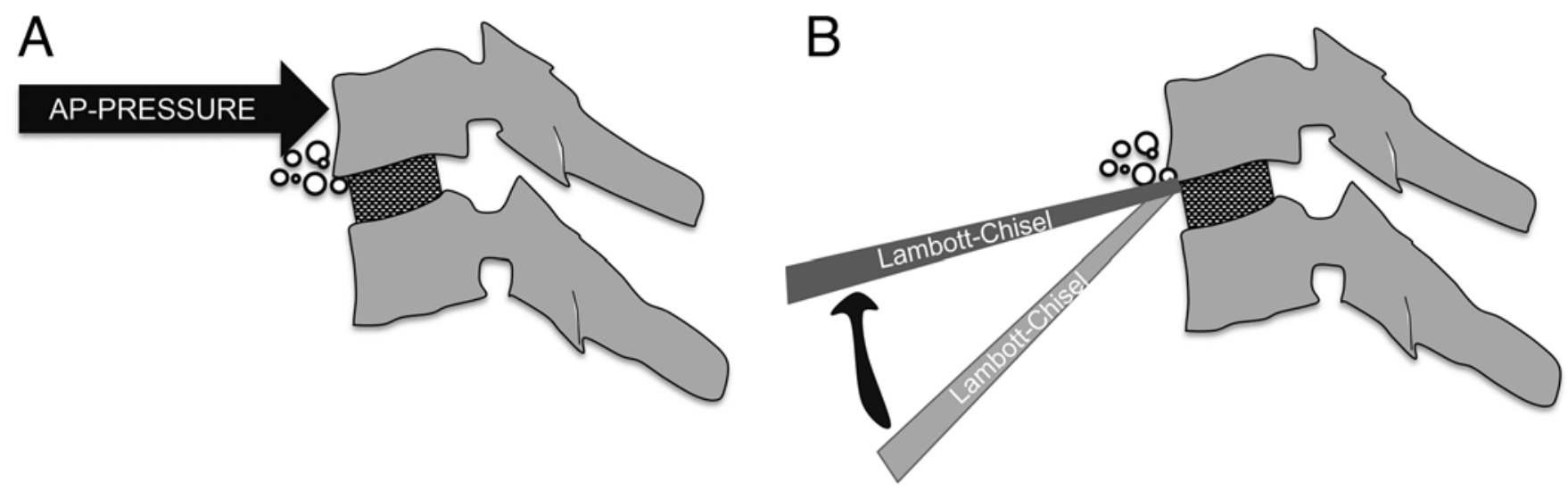

FIG. 2. A: AP translation test. B: Craniocaudal angulation test. 
TABLE 2. Identification of osseous union with CT scan criteria compared with intraoperative findings

\begin{tabular}{lcccc}
\hline & \multicolumn{4}{c}{ Values for CT vs Intraop Findings (\%) } \\
\cline { 2 - 5 } \multicolumn{1}{c}{ CT Scan Criterion } & Sensitivity & Specificity & PPV & NPV \\
\hline $\begin{array}{c}\text { Bridging bone on }>1 \text { CT slice, } \\
\text { no lucency }\end{array}$ & 100 & 52 & 34 & 100 \\
\hline Bridging bone & 100 & 28 & 26 & 100 \\
\hline Bridging bone on $\geq 3$ CT slices & 100 & 58 & 38 & 100 \\
\hline $\begin{array}{l}\text { Upper endplate fusion } \\
\text { Lower endplate fusion }\end{array}$ & 93 & 16 & 22 & 92 \\
\hline Bridging bone anterior to cage & 60 & 87 & 53 & 90 \\
\hline $\begin{array}{c}\text { Bridging bone posterior to } \\
\text { cage }\end{array}$ & 47 & 75 & 32 & 85 \\
\hline $\begin{array}{c}\text { Osseus integration of cage at } \\
\text { both endplates }\end{array}$ & 93 & 22 & 23 & 92 \\
\hline Bridging bone w/in cage & 84 & 23 & 22 & 88 \\
\hline
\end{tabular}

explored segment occurred in several patients in whom osseous union was expected on the basis of the finding of bridging bone on $\geq 3 \mathrm{CT}$ slices, the assessment criterion evaluated in this study. A possible explanation for these results is the low prevalence of union in our study patients. However, this study population is a realistic representation of patients with persistent or recurring symptoms after prior ACDF, with the patients also fulfilling the criteria for revision surgery on the basis of adjacent level disease or residual stenosis at the prior operated level. Therefore, the NPV and PPV findings should be taken into account when deciding whether or not to offer a patient revision surgery, especially when CT scans do not show obvious evidence of a nonunion but the patient's cervical symptoms and pain pattern might indicate the presence of pseudoarthrosis..$^{5}$

The discrepancy between the finding of visible bone bridging on CT, especially on fewer than $3 \mathrm{CT}$ slices, and observed intraoperative motion can be elucidated by drawing parallels with the concept of a sitting chair. In this example, the ROM is dependent on the number and position of the chair legs. Therefore, even with a few bone bridges visible, particularly if they do not connect the endplates, substantial motion can still be present to an extent that is directly proportional to our findings of increased specificity with increased number of CT slices with bridging bone present and our finding of higher specificity when the bone is bridging only the endplates, either anteriorly or posteriorly to the cage (Fig. 3). Furthermore, macromotions are not to be expected in these patients with nonunion, as they already have degenerative cervical spine disease, which transmits the stress-strain curve of a spinal level and its related neutral and elastic zones in a manner similar to material that is stiffer and more brittle than that found in a healthy spine.? Therefore, micromovements are the most common entity of nonunion in these patients.

\section{Value of CT-Based Criteria}

All 44 patients who met the inclusion criteria were included in this study. Some level of selection bias was inevitably present. The retrospective character of the study did not influence the indications for surgery. This type of patient selection likely made the prevalence of nonunion higher than the median expected in the population and, with that, may have negatively influenced the PPV find-
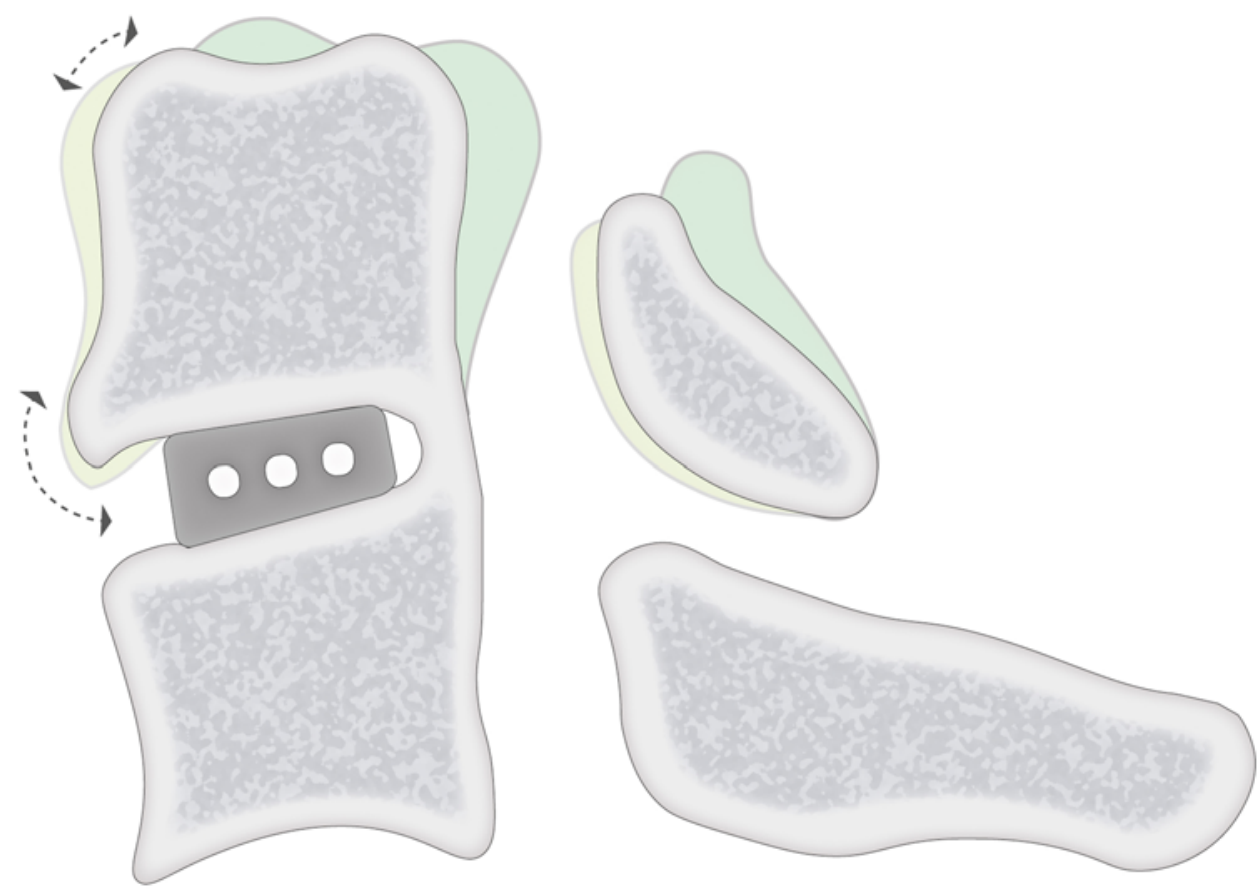

FIG. 3. Example of ROM (dashed lines with arrows represent macromotions and green shaded areas represent maximum movements forward and backward). Figure is available in color online only. 
ings. Negative influence on NPV, however, is not considered to be likely, given the maximum sensitivity present in the data.

All CT reviews were done by an experienced neuroradiologist (C.U.), who was selected for this study because of his more than 30 years of experience in the clinical field and renowned expert status within the Cervical Spine Research Society and American Society of Neuroradiology. Therefore, there may have been a difference in experience between the radiologist in this study and interpreters in daily practice, which could have led to interpretation variation within our study; however, previous studies have demonstrated good interobserver reliability for CT assessment, even with fewer experienced observers. . $^{1,4,6,15}$ In addition, observer dependency as well as the CT assessment process itself can be expected to have no significant influence on the final results, since the differences between $\mathrm{CT}$ assessment and the intraoperative exploration of fusion were large.

In the literature there has been discussion about the expected fusion rates and subsidence when PMMA is used in ACDF. With a reported fusion rate in the literature of 46\%-66\% with the use of PMMA, fusion can be achieved, and comparative studies show no statistically significant differences in fusion achieved with PMMA and that achieved with PEEK cages. Therefore, the authors did not expect the type of cage used to influence the study results, and no subanalyses of different cage types were performed. ${ }^{2,8,17}$

In our study, some of the items were scored on coronal $\mathrm{CT}$ views and some on sagittal CT views. Interestingly, items assessed in the coronal plane had higher sensitivity, while items in the sagittal plane had higher specificity. This observation may be of some diagnostic value.

Rhee et al ${ }^{16}$ stated that while intraoperative exploration has the disadvantage of being a subjective test dependent upon the skill, experience, and interpretation of the surgeon, it is considered as the standard of reference at this time. To minimize bias in our study, intraoperative exploration was performed by experienced senior spine surgeons.

\section{Comparison With the Literature}

Previous studies have used intraoperative validation to confirm the diagnostic accuracy of CT-based criteria. ${ }^{1,6,20}$ However, a major drawback of many previous studies is the use of a posterior approach to assess fusion. A posterior approach demonstrates a significantly greater fusion rate compared with the anterior approach..$^{12}$ This discrepancy can be explained by the previously discussed chair theory and the mobility of posterior osseous elements. In addition, micromovements are likely to be missed in posterior fusion evaluation.

Buchowski et al. ${ }^{1}$ performed anterior revision surgery to assess fusion in their study. Unfortunately, however, their study included only 14 patients and focused on intraobserver reliability without sensitivity or specificity calculations. Therefore, no comparisons with our study, nor conclusions about diagnostic accuracy, can be drawn with the help of this study.

Ghiselli et al. ${ }^{6}$ assessed CT scans with intraoperative findings. They used the same CT criteria as Buchowski et al., but as predictors of nonunion. So in contrast to our study, a positive test was stated as "no briding bone on CT." Ghiselli et al. found a sensitivity of $69.2 \%$, specificity of $100 \%$, PPV of $100 \%$, and NPV of $73.3 \%$. These values are in concordance with our findings, given their imaging criteria for nonunion; however, their study included only 10 cases. All of their patients were operated on posteriorly, which does not match our population and, as previously stated, motion cannot be sufficiently ruled out with a posterior surgical approach.

Song et al. ${ }^{20}$ retrospectively weighted CT findings against intraoperative findings and performed revision surgery on 48 patients anteriorly and 62 patients posteriorly. These authors defined fusion properly and divided their data into extragraft bone bridging and intragraft bone bridging cohorts. However, only $23 \%$ of their revised spinal levels had a cage. The other patients had corticocancellous graft inserted, which makes fusion assessment easier. Song et al. found that extragraft bone bridging had a sensitivity of $98.7 \%$ and specificity of $92.1 \%$ and intragraft bone bridging had a sensitivity of $90.6 \%$ and specificity of $69.3 \%$. We also evaluated intragraft bone bridging in our study, but our results are discordant with those of Song et al., which suggests that this scoring item is not a reliable predictor of union and therefore should not be used for this purpose.

\section{Clinical Significance}

Patients with nonunion after ACDF have worse clinical outcomes, $7,10,21$ and revision surgeries have shown good results, ${ }^{12}$ making bone union the desired outcome in this patient category. However, the diagnosis of nonunion is still controversial as nonunion rates reported in the literature vary widely and are influenced by length of followup, number of fused levels, quality of interbody fusion bed preparation, bony graft material and substitutes, cervical alignment and use of a cervical plate, and more importantly, by the type of follow-up.

Different imaging modalities and manner of scoring influence the diagnostic accuracy of nonunion. 3,7,10,14,18,21 Therefore, a universally accepted scoring system is mandatory. Our study suggests that, given its sensitivity, the $\mathrm{CT}$ criterion of bridging bone on $\geq 3 \mathrm{CT}$ images can be successfully used to support the decision-making process in patients who are symptomatic after ACDF and with the clinical suspicion of a nonunion. The absence of this bridging bone is a highly sensitive indicator of nonunion.

When a nonunion is suspected in a patient with impressive clinical symptoms, surgical revision can be offered. ${ }^{9}$ Before proceeding to an invasive surgical exploration, however, one could consider performing PET CT in patients with high clinical suspicion of nonunion without clear evidence of nonunion on a CT scan. ${ }^{5}$ However, although PET CT may appear promising, appropriate correlation studies have yet to be performed. The routine diagnostic value of PET CT is still unknown. ${ }^{16}$ Furthermore, flexion-extension radiographs are sometimes used as a modality to assess pseudoarthrosis, but this technique has a poor predictive value compared with intraoperative findings. ${ }^{1}$ Therefore, we do not recommend flexion-extension radiographs for 
the assessment of pseudoarthrosis. Surgical exploration remains the gold standard.

Our study suggests that nonunion is underdiagnosed in this patient category when using CT as the diagnostic modality. Physicians should take the stated sensitivity and particularly low specificity into account when judging CT scan findings. The decision regarding surgical exploration and revision depends on both clinical symptoms and imaging findings. The diagnosis of nonunion could be wrongly rejected, which may lead to withholding of proper treatment from some symptomatic patients.

\section{Conclusions}

The CT scan criterion of bridging bone on $\geq 3$ CT slices yields the highest accuracy in assessing bony union after ACDF. However, because of the high NPV of this method, assessment of preoperative CT scans using this criterion leads to underestimates of the rate of nonunion, which should be taken into account when assessing a symptomatic patient after prior ACDF.

\section{References}

1. Buchowski JM, Liu G, Bunmaprasert T, Rose PS, Riew KD: Anterior cervical fusion assessment: surgical exploration versus radiographic evaluation. Spine (Phila Pa 1976) 33:1185-1191, 2008

2. Cabraja M, Koeppen D, Lanksch WR, Maier-Hauff K, Kroppenstedt S: Polymethylmethacrylate-assisted ventral discectomy: rate of pseudarthrosis and clinical outcome with a minimum follow-up of 5 years. BMC Musculoskelet Disord 12:140, 2011

3. Cauthen JC, Kinard RE, Vogler JB, Jackson DE, DePaz OB, Hunter OL, et al: Outcome analysis of noninstrumented anterior cervical discectomy and interbody fusion in 348 patients. Spine (Phila Pa 1976) 23:188-192, 1998

4. Epstein NE, Silvergleide RS, Black K: Computed tomography validating bony ingrowth into fibula strut allograft: a criterion for fusion. Spine J 2:129-133, 2002

5. Fischer DR, Zweifel K, Treyer V, Hesselmann R, Johayem A, Stumpe KDM, et al: Assessment of successful incorporation of cages after cervical or lumbar intercorporal fusion with $[(18) \mathrm{F}]$ fluoride positron-emission tomography/computed tomography. Eur Spine J 20:640-648, 2011

6. Ghiselli G, Wharton N, Hipp JA, Wong DA, Jatana S: Prospective analysis of imaging prediction of pseudarthrosis after anterior cervical discectomy and fusion: computed tomography versus flexion-extension motion analysis with intraoperative correlation. Spine (Phila Pa 1976) 36:463-468, 2011

7. Kaiser MG, Mummaneni PV, Matz PG, Anderson PA, Groff MW, Heary RF, et al: Management of anterior cervical pseudarthrosis. J Neurosurg Spine 11:228-237, 2009

8. Klingler JH, Krüger MT, Sircar R, Kogias E, Scholz C, Volz $F$, et al: PEEK cages versus PMMA spacers in anterior cervical discectomy: comparison of fusion, subsidence, sagittal alignment, and clinical outcome with a minimum 1-year follow-up. ScientificWorldJournal 2014:398396, 2014

9. Kuhns CA, Geck MJ, Wang JC, Delamarter RB: An outcomes analysis of the treatment of cervical pseudarthrosis with posterior fusion. Spine (Phila Pa 1976) 30:2424-2429, 2005

10. Lee DH, Cho JH, Hwang CJ, Lee CS, Cho SK, Kim C, et al: What is the fate of pseudarthrosis detected 1 year after ante- rior cervical discectomy and fusion? Spine (Phila Pa 1976) 43:E23-E28, 2018

11. Marawar S, Girardi FP, Sama AA, Ma Y, Gaber-Baylis LK, Besculides MC, et al: National trends in anterior cervical fusion procedures. Spine (Phila Pa 1976) 35:1454-1459, 2010

12. McAnany SJ, Baird EO, Overley SC, Kim JS, Qureshi SA, Anderson PA: A meta-analysis of the clinical and fusion results following treatment of symptomatic cervical pseudarthrosis. Global Spine J 5:148-155, 2015

13. Oshina M, Oshima Y, Tanaka S, Riew KD: Radiological fusion criteria of postoperative anterior cervical discectomy and fusion: a systematic review. Global Spine J 8:739-750, 2018

14. Park DK, Rhee JM, Kim SS, Enyo Y, Yoshiok K: Do CT scans overestimate the fusion rate after anterior cervical discectomy and fusion? J Spinal Disord Tech 28:41-46, 2015

15. Ploumis A, Mehbod A, Garvey T, Gilbert T, Transfeldt E, Wood K: Prospective assessment of cervical fusion status: plain radiographs versus CT-scan. Acta Orthop Belg 72:342-346, 2006

16. Rhee JM, Chapman JR, Norvell DC, Smith J, Sherry NA, Riew KD: Radiological determination of postoperative cervical fusion: a systematic review. Spine (Phila Pa 1976) 40:974-991, 2015

17. Schröder J, Wassmann H: Polymethylmethacrylat (PMMA) in der Halsbandscheibenchirurgie-gegenwärtige Situation in Deutschland. Zentralbl Neurochir 63:33-36, 2002

18. Shriver MF, Lewis DJ, Kshettry VR, Rosenbaum BP, Benzel EC, Mroz TE: Pseudoarthrosis rates in anterior cervical discectomy and fusion: a meta-analysis. Spine J 15:2016-2027, 2015

19. Smith GW, Robinson RA: The treatment of certain cervicalspine disorders by anterior removal of the intervertebral disc and interbody fusion. J Bone Jt Surg Br 40:607-624, 1958

20. Song KS, Chaiwat P, Kim HJ, Mesfin A, Park SM, Riew $\mathrm{KD}$ : Anterior cervical fusion assessment using reconstructed computed tomographic scans: surgical confirmation of 254 segments. Spine (Phila Pa 1976) 38:2171-2177, 2013

21. Vavruch L, Hedlund R, Javid D, Leszniewski W, Shalabi A: A prospective randomized comparison between the Cloward procedure and a carbon fiber cage in the cervical spine: a clinical and radiologic study. Spine (Phila Pa 1976) 27:1694-1701, 2002

\section{Disclosures}

The authors report no conflict of interest concerning the materials or methods used in this study or the findings specified in this paper.

\section{Author Contributions}

Conception and design: Koller. Acquisition of data: Ullrich, Mayer, Koller. Analysis and interpretation of data: van Bilsen, Koller. Drafting the article: van Bilsen. Critically revising the article: van Bilsen, Ferraris, Koller. Reviewed submitted version of manuscript: all authors. Approved the final version of the manuscript on behalf of all authors: van Bilsen. Administrative/technical/material support: Koller. Study supervision: Koller. Ethical review: Koller. Surgical procedures: Koller.

\section{Correspondence}

Martine W. T. van Bilsen: Radboud University Medical Center, Nijmegen, the Netherlands. martine.vanbilsen@radboudumc.nl. 